\title{
Supraharmonics Emission Assessment of Multi-level Converters Applied for Photovoltaic Grid-Connected Inverters
}

\author{
T. Busatto, A. Larsson, S. K. Rönnberg and M. H. J. Bollen \\ Electrical Power Engineering \\ Luleå University of Technology (LTU) \\ 931 87, Skellefteå, Sweden \\ E-mail: tatiano.busatto@ltu.se
}

\begin{abstract}
Topologies for different DC-AC converters used on grid-connected photovoltaic (PV) inverters are analysed and compared within this paper. The main focus is to evaluate the supraharmonic emission in the frequency range 2 to $150 \mathrm{kHz}$. For this study three topologies are evaluated: Neutral Point Clamped (NPC), the Cascaded H-bridge (CHB) and the Flying Capacitor (FC). To approximate the operation closer to a real scenario, the converters are analysed under the presence of voltage waveform distortion in the power supply. The simulation is performed using PSpice for the converters and Simulink for the grid. The characterization is made by the quantification of harmonics and supraharmonics, and also by the frequency domain analysis of the output current. Finally, a comparison of the chosen technologies is carried out, given a better understanding on the elements which exert influence on this type of emission.
\end{abstract}

\section{Key words}

Supraharmonics, power electronics, power quality, photovoltaic inverter, multi-level converters.

\section{Introduction}

Photovoltaic (PV) power generation has shown a high growth in recent years. The main reasons for the spread of this technology are governmental incentives and reduction in cost for both PV panels and inverters.

According to the latest International Energy Agency (IEA) report on Photovoltaic Power System (PVPS) [1], the growth of the cumulative installed capacity was at 25\% in 2015. Most of these installations were small rooftop installations, using small-scale grid-connected PV inverters. Inside of these inverters, technologies using multi-level inverters (MLI) are commonly used.

One of the main advantages of using multi-level converters is the improvement of the output waveform shape for current and voltage. Usually the current is slightly distorted and close to a unity power factor. Recent studies presented in [2] and [3] have shown that the effort to increase the power factor, and decreasing the harmonic content in the lower-frequency range of the output current, has led to an increase of the emission in the supraharmonics range.
This work explores aspects related to PV inverter emission, already presented in [4]. The goal is to quantify the emission on the Point of Common Coupling (PCC), taking into account the primary and secondary emission [5] for different combinations of inverter topology. Primary emission refers to the emission originating from the converter, while secondary emission refers to the emission originating from the grid. Primary emission are related to the converter operation, which is based on the combination between the topology and modulation strategy. In order to simulate the interaction a distorted voltage waveform is assumed at the terminals of the converter. Two distorted waveforms are used: flat-top (FT) and pointed-top (PT).

All the converter topologies in this work were simulated using OrCAD PSpice ${ }^{\circledR}$ software in order to consider non-ideal devices and to approximate as closely as possible to a real operation. Deadtime and dynamic response of the switching devices are taken into account using dedicated gate drivers for simulation.

Considering the interaction between the primary and secondary emission, the qualification of emission is performed. The assessment of the emission is based on the analysis of FFT spectrum.

In the following text, first the fundamentals related to supraharmonics, is described. In Section 3 and 4, the chosen converter topologies are presented, followed by a brief explanation about modulation strategies. Section 5 describes the operational conditions and test setup for simulation, followed by the simulation results, in Section 6. Finally, in Section 7, conclusions are made.

\section{Supraharmonic Emission}

Emission in the range of 2 to $150 \mathrm{kHz}$ has caught the attention of many researchers in recent years. Several works have already been conducted to reveal the impacts of this type of emission (e.g., [7], [8]). The last has been more widespread and characterized as "supraharmonics" [9], where the prefix "supra" in this context means beyond the harmonic range, limited to $150 \mathrm{kHz}$. Fig. 1 shows an example of voltage and current waveform obtained from a 63W LED lamp analysed at the 
laboratory of Luleå University of Technology. The current is almost sinusoidal except from some small distortion around the zero crossing at both positive and negative peak of the current. This waveform distortion originates from the switching devices in the Active Power Factor Correction (APFC), and appears in the supraharmonic range [2]. A similar effect occurs for the PV inverters using multi-level DC-AC converters. The combination of switching methods and device topologies aims to create the current as close as possible to a pure sinusoidal waveform. However, the effects of the high frequencies used to drive the switching devices and interaction between frequency components starts to be evident when analysing the supraharmonics range.

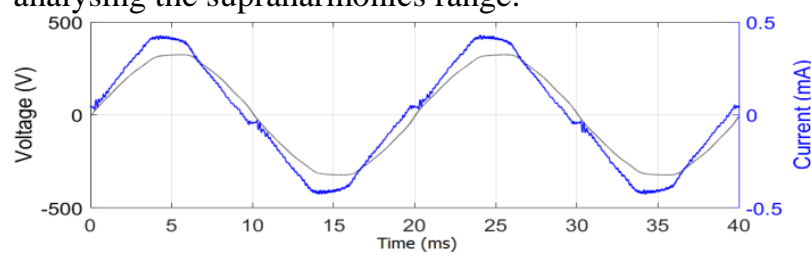

Fig. 1. Voltage (blue) and current (orange) waveform drawn by a 63W LED lamp with APFC.

Recent studies have revealed some behaviour related to supraharmonics. It is already known for example that the supraharmonic current mainly flow between individual devices instead of into the grid [10]. However, the impact caused by the spreading of supraharmonics in terms of performance and life length of equipment has not been investigated for PV inverters. First, it is necessary to investigate how these frequency components behave on the current output of the PV inverters.

\section{Multi-level Converter Topologies}

Multi-level Voltage Source Converters (VSC) is mainly composed by a topology of switching devices, normally MOSFETs and IGBTs, and auxiliary devices such as capacitors and diodes. The main aim of the converter is to compose a sinusoidal voltage waveform from a DC source. The waveform will depend on the number of levels and carrier frequency which drives the devices. The number of levels defines the number of steps in the voltage output. The higher the frequency and number of levels, the closer to the reference the waveform will be. Following the multi-level topologies used in this work are described.

\section{A. Neutral Point Clamped (NPC)}

NPC is the most commonly used MLI topology. The electrical potential between the PV cell and the ground is fixed by connecting the neutral from the grid to a constant potential, resulting from a DC link capacitive divider [11]. The main advantage of this topology is that a single-phase NPC achieves immunity from ground leakage currents. The drawback is the difficulty to ensure the voltage balance in the DC-link capacitors. The higher the number of levels, the more difficult it is to keep the balance. A basic structure of a five level NPC is shown in Fig. 2(a).

\section{B. Flying Capacitors (FC)}

Fig. 2(b) illustrates the basic topology of a five level Flying Capacitors (FC) converter. Compared to NPC, the
FC topology presents some advantages, mainly because it requires no voltage balance effort. In addition, no clamping diodes are needed. Instead of diodes, flying capacitors are used which give a zero voltage level between the connections of the capacitor and the load terminal. Another advantage is the capacity of modularization which allows the converter to reach higher voltage output levels, keeping the same voltage level between the switching devices, and in consequence, keeping the same voltage between the flying capacitors.

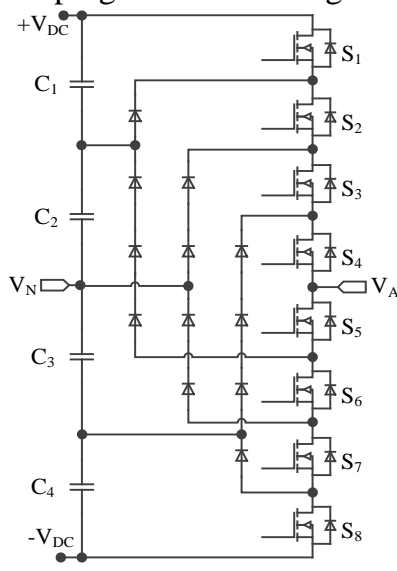

(a)

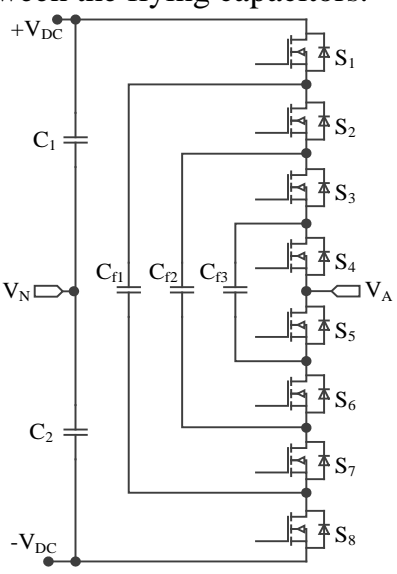

(b)
Fig. 2. Basic structures of five level multi-level converters: (a) Neutral Point Clamped (NPC), (b) Flying Capacitors (FC).

\section{Cascaded H-Bridges (CHB)}

This topology, shown in Fig. 3, consists in serially connected H-bridges, supplied by isolated DC voltage sources. Since the voltage sources are decoupled, the voltage levels can be scalable. In addition, this topology allows less voltage stress on the switching devices. The drawback is the need of each H-bridge being fed by independent voltage sources. In other words, the sources need to be floating, without common connection between them.

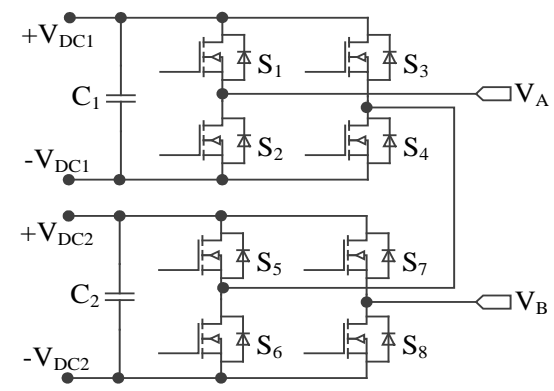

Fig. 3. Basic structure of a five level Cascaded H-Bridges (CHB) topology.

From the presented structures, it can be observed that several low voltage cells per arm allow high scalability. The converters can thus be connected to grids operating with high voltage. In addition, these topologies achieve a better quality of the output voltage.

To accomplish the control requirements for these topologies, more robust control strategies are required.

\section{Modulation Strategies}

In this section the modulation strategies selected are described. Both of them use Multicarrier-based PWM as 
main strategy, several triangular carrier signals are used to convey information from the reference signals [12].

\section{A. Phase-Shifted PWM (PS-PWM)}

The Phase-Shifted PWM is based on the unipolar PWM strategy. It is the most commonly used technique for FC and CHB topologies [21]. The base of this technique consists in the use of $(m-1)$ triangular carriers, phase shifted by $360 \%(m-1)$ between the carriers signals, $m$ being the number of voltage levels as shown in Fig. 4.

The main advantage is that the switching frequency is $(m-1)$ times the switching frequency of each cell. The result is a reduction of the switching frequency for each cell, reducing the switching losses.

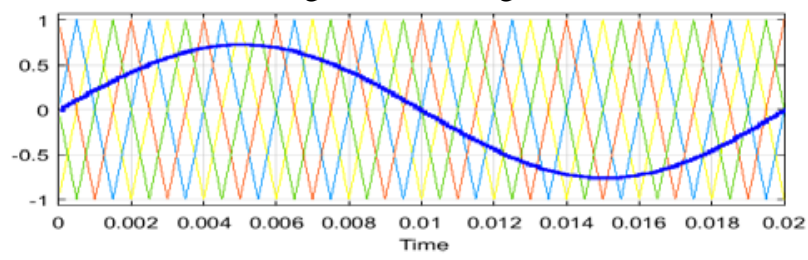

Fig. 4. PS-PWM carrier disposition arrangement.

\section{B. Level-Shifted PWM (LS-PWM)}

The LS-PWM is most commonly used in NPC converters [21]. The basic operation of LS-PWM is based on the variation of the DC level of the carrier signal. This allows the abstention of a vertical configuration of the carrier signals. Since all carriers are in phase, this strategy leads to less distorted line voltages, compared to PS-PWM.

Depending on the phase disposition, three modes are possible: Phase Disposition (PS-PD), Phase Opposition Disposition (PS-POD), and Alternate Phase Opposition Disposition (PS-APOD) as shown in Fig. 5.
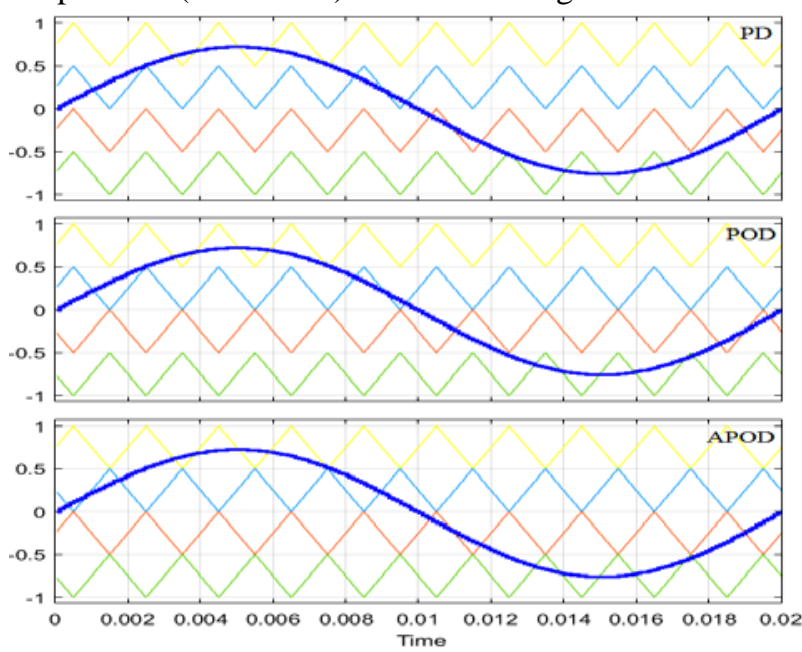

Fig. 5. LS-PWM carrier disposition arrangement.

\section{Test Setup}

To enable the assessment of the different converter topologies, modulation strategies, and grid variations a simulation test setup was developed. The simplified schema employed is shown in Fig. 6. The assessment of all voltage and current results were obtained from the immediate point after the LCL filter. The setup is more or less based on typical installation employing single-phase PV inverters connected to public low-voltage (LV) networks. Since the main objective of this study is to evaluate the emission from the DC-AC converter, PV array, DC-DC converter, and their respective controls are not considered in this setup. Instead, an ideal DC source is considered.

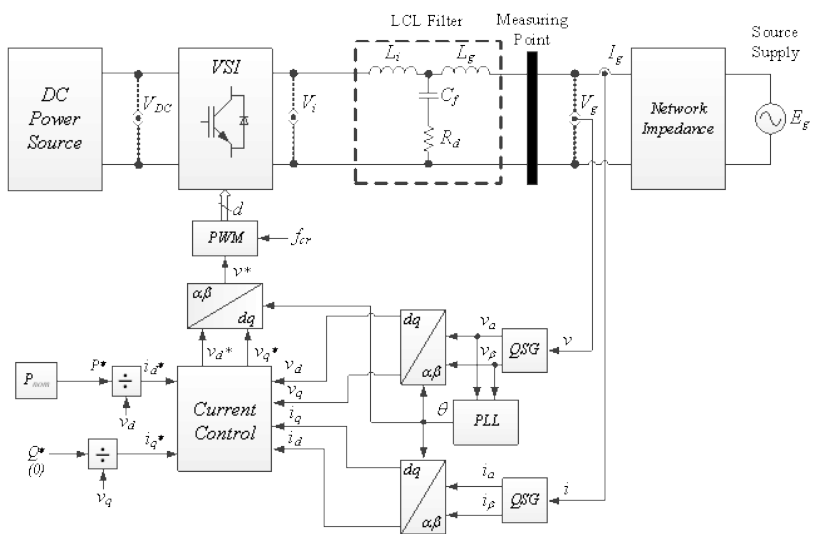

Fig. 6. Simplified scheme employed for the simulations.

A rated power of $3.6 \mathrm{~kW}$ for the PV inverter was chosen. The decision was made considering that level is suitable for single-phase PV inverters, allowing lower installation costs and reduced conduction losses to higher input-voltage levels. Furthermore, it meets the regulation requirements for several countries, for single-phase distributed generation connection (e.g. power up to 4.6 $\mathrm{kVA}$ in Germany [14]), and below the current limit of 16 $A$ in accordance to IEC 61000-3-2 [6]. Table I summarizes the main parameters for simulation test.

Table I - Main parameters of the simulation test setup.

\begin{tabular}{|l|c|}
\hline Parameter & Value \\
\hline Grid voltage & $230 \mathrm{~V}$ \\
\hline Grid frequency & $50 \mathrm{~Hz}$ \\
\hline Output power of the inverter & $3.6 \mathrm{kVA}$ \\
\hline Switching frequency & $20 \mathrm{kHz}$ \\
\hline Power factor & 1.0 \\
\hline
\end{tabular}

The VSI block allows the selection of the three five level MLI topology under analysis. In this block, the simulation runs on PSpice. The switching devices are the same for all simulations, (i.e. IRF840, with $V_{D S}=500 \mathrm{~V}$ $R_{\text {on }}=0.85 \Omega, t_{\text {on }}=14 \mathrm{~ns}$, and $t_{\text {off }}=49 \mathrm{~ns}$ ).

The modulation strategies are chosen on the PWM block, keeping the switching frequency fixed for all setup combinations.

\section{A. Active-/Reactive-Power Controller}

To achieve the right power flow towards to the grid, a power control was modelled. The objective is to control the instantaneous active and reactive power. Since a unity power factor is desired, the reference for reactive power is kept constant at zero. The reference for the active power is the inverter rated power. A currentmode controller based on $d q$-frame was used for that. The advantage of this design is that the control variables are DC quantities in the steady state. That makes the compensator design easy in variable-frequency scenarios. One of the drawbacks is the poor disturbance rejection capability and the steady state error for the sinusoidal reference [15]. In addition, to keep the converter synchronized with the grid a Phase-Locked Loop (PLL), based on a T/4 transport delay is used. 


\section{B. Output Filter}

In VSC converters, the output filter must fulfil two requirements. First, it must have an inductive characteristic in order to guarantee the proper dynamics operation of the converter. Second, it must attenuate the switching frequency from the PWM carrier and side-band harmonics [15]. For the purpose of this study a LCL filter with passive damping in series was used. This third order filter provides $60 \mathrm{~dB}$ per decade attenuation, and the damping reduces the stability problems due to the undesired resonances at certain frequencies. The transfer function for the filter is given as:

$$
H_{f}(s)=\left.\frac{I_{g}(s)}{V_{g}(s)}\right|_{V_{g}=0}=\frac{C_{f} R_{d} s+1}{L_{i} L_{g} C_{f} s^{3}+C_{f} R_{d}\left(L_{i}+L_{g}\right) s^{2}+\left(L_{i}+L_{g}\right) s}
$$

From the rated characteristics of the system, and knowing the converter switching frequency, the values for the LCL filter can be calculated. A limit for the output current ripple equal to $10 \%$ of the rated current was considered. The device values and magnitude and phase plot of the filter is shown in Table II and Fig. 7 respectively.

Table II - Output filter parameters and their chosen values.

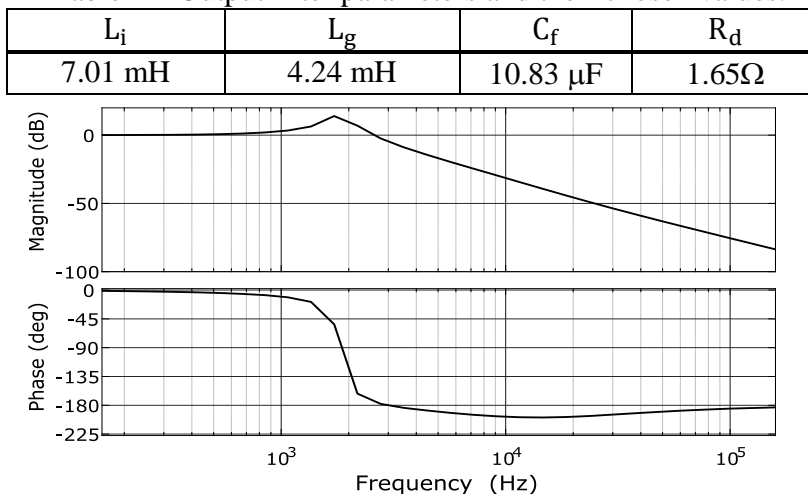

Fig. 7. Filter magnitude and phase plot of $H_{f}(s)$ using the selected filter components values.

\section{RLC Load}

The local load in the LV distribution grid is modelled as a RLC (resistive-inductive-capacitive) parallel circuit, according to IEEE Std. 1547 [16]. The RLC values are calculated as follow:

$$
R=\frac{V^{2}}{P} \quad L=\frac{V^{2}}{2 \pi f P Q_{f}} \quad C=\frac{P Q_{f}}{2 \pi f V^{2}}
$$

The real power demand, matches the rated inverter output power $P$, and the capacitive and inductive elements are resonant at the rated grid frequency with a circuit quality factor of $Q_{f}=1$. The reactive power absorbed by $L$ and the reactive power generated by $C$ is equal, resulting in a parallel RLC resonant load equivalent to the pure resistance load.

\section{Waveform Distortion}

In order to simulate multi-level converters near to a real operation, some possible characteristics in the voltage and source are assessed. For this purpose, two different voltage distortions are applied at the converter terminals: a flat-top (FT) and a pointed-top (PO) waveform. The definitions for these waveforms are described in IEC 61000-4-13 [17]. As reference, a sinusoidal waveform is used. The flat-top voltage is caused by the use of single-phase rectifiers, while industrial grids often have a pointed-top voltage generated by the use of six-pulse rectifiers [13]. As reference, the first odd harmonics and the Total Harmonic Distortion values $\left(\boldsymbol{T H} \boldsymbol{D}_{U}\right)$ used for the simulations are shown in Table III.

Table III - Characteristics of the voltage waveforms used in the

\begin{tabular}{|c|c|c|c|c|}
\hline \multicolumn{2}{|c|}{$\begin{array}{c}\text { Voltage } \\
\text { Harmonics }\end{array}$} & $\begin{array}{c}\text { Sinusoidal } \\
(\mathrm{SI})\end{array}$ & $\begin{array}{c}\text { Flat-top } \\
(\mathrm{FT})\end{array}$ & $\begin{array}{c}\text { Pointed-top } \\
\text { (PO) }\end{array}$ \\
\hline \multirow{4}{*}{$\begin{array}{l}\text { Magnitude } \\
\text { (V) }\end{array}$} & 1 & 230,00 & 223,50 & 230,00 \\
\hline & 3 & -- & 5,3 & 7,0 \\
\hline & 5 & -- & 3,7 & 7,0 \\
\hline & 7 & -- & 2 & 0,11 \\
\hline \multirow{4}{*}{$\begin{array}{c}\text { Angle } \\
\left({ }^{\circ}\right)\end{array}$} & 1 & 0 & 0 & 0 \\
\hline & 3 & -- & 0 & 180 \\
\hline & 5 & -- & 180 & 0 \\
\hline & 7 & -- & 0 & 0 \\
\hline \multicolumn{2}{|c|}{$T H D_{U}(\%)$} & $\approx 0$ & 3,1 & 4,3 \\
\hline
\end{tabular}
simulations, according to [13].

\section{E. Network Impedance}

The presence of inductances (L) and capacitances (C) at the loads and conductors may cause resonances between the network devices and the converter. This may affect the dynamics operation of PV inverter, as well as other loads connected at the connection point. Parallel and series resonance are possible, depending on where the $\mathrm{L}$ and $\mathrm{C}$ elements are arranged in the system. For both, the resonance frequency can be calculated as follow:

$$
f_{\text {res }}=\frac{1}{2 \pi \sqrt{L C}}
$$

In the equation, $\mathrm{L}$ and $\mathrm{C}$ are the equivalent inductance and capacitance in parallel or series network.

Parallel resonance implies the increase of the impedance at the resonance frequency point, while the series impedance reduces the impedance at the resonance frequency. In this study, only the series resonance is evaluated, since it is caused mainly by the considerable presence of electronic loads in the households, which contains capacitors connected between the terminals. An equivalent capacitance of $3 \mu \mathrm{F}$ was considered, following the reference values given by the authors in [18] for resonance studies. The main characteristics of the network impedance were adjusted in accordance with [19], which gives guidance for determining the reference impedances for use in determining disturbance characteristics of electrical equipment. Two scenarios are considered in this work: a model using only the reference impedance, referred to Z1, and a model with a parallel capacitance plus the reference impedance, referred to $\mathrm{Z} 2$.

\section{Simulation Results}

To analyse the results, simulations covering all possible combination were performed, for instance: MLI topology, modulation strategy, power supply distortion, and network characteristic. In total, 30 configurations were evaluated. Since the power controller requires a stabilization time to reach the reference, all simulation results were obtained starting from 0.1 second after the beginning of the simulation. Fig. 8 shows the dynamics 
behaviour of the power controller for the active (P) and reactive power $(\mathrm{Q})$.

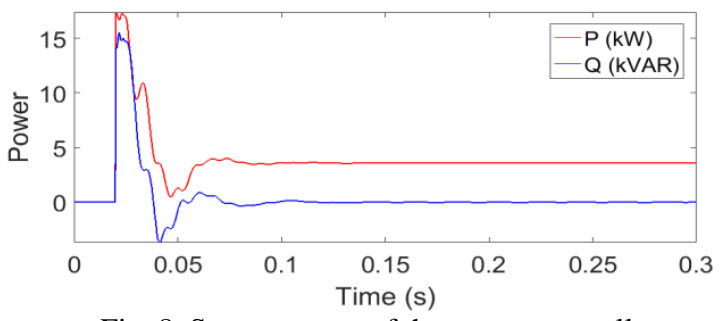

Fig. 8. Step response of the power controller.

Focusing on the output current, first, the Total Harmonic Distortion of current $\left(T H D_{I}\right)$ was computed, according to [20], in the range 0 to $2 \mathrm{kHz}$. The overall simulated results are summarized in Table IV.

Table IV - Total Harmonic Distortion of current $\left(T H D_{I}\right)$, expressed as a percentage of the rated current.

\begin{tabular}{|c|c|c|c|c|c|c|}
\hline \multirow{2}{*}{$\begin{array}{l}\text { Source } \\
\text { Supply }\end{array}$} & \multirow{2}{*}{$\begin{array}{l}\text { Network } \\
\text { Config. }\end{array}$} & \multicolumn{3}{|c|}{ NPC } & \multirow{2}{*}{$\begin{array}{l}\text { FC } \\
\text { FS }\end{array}$} & \multirow{2}{*}{$\frac{\mathrm{CHB}}{\mathrm{FS}}$} \\
\hline & & PD & POD & APOD & & \\
\hline SI & $\mathrm{Z} 1$ & 3.19 & 3.39 & 3.52 & 3.10 & 3.07 \\
\hline FT & Z & 1 & 16.31 & 6.15 & 13.97 & 10.70 \\
\hline $\mathrm{PO}$ & $\mathrm{Z1}$ & 22.42 & 22.04 & 22.69 & 20.63 & 16.22 \\
\hline SI & $\mathrm{Z} 2$ & 3.16 & 3.41 & 3.54 & 3.09 & 3.11 \\
\hline FT & $\mathrm{Z} 2$ & 15.98 & 16.35 & 16.16 & 15.80 & 10.70 \\
\hline $\mathrm{PO}$ & Z2 & 22.48 & 22.09 & 22.75 & 23.30 & 16.30 \\
\hline
\end{tabular}

From the Table IV, it can be seen that the CHB topology, in average, achieve the better performance compared to the other. Regarding modulation strategy, for NPC converters, there is no expressive difference in the results related to the choice of them. About the parallel capacitance in the grid (Z2), it can be seen that it contributed slightly to the increase in distortion. To illustrate the converter waveform composition, Fig. 9 shows the voltage and current waveform taken immediately after the converter, without the LCL filter attenuation, for the CHB-PS-SI-Z1 and FCA-PS-PO-Z2 configurations, lower and higher $T H D_{I}$ results respectively.

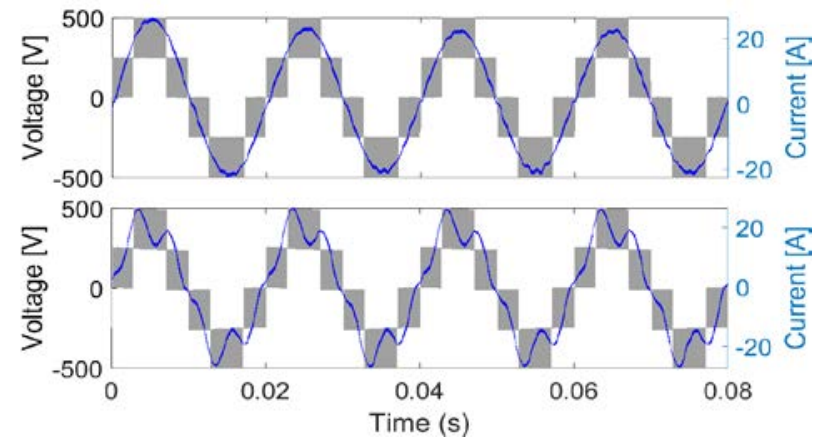

Fig. 9. Output voltage and current of the converter for CHB-PSSI-Z1 (upper) and FCA-PS-PO-Z2 (lower).

As can be seen in Fig. 9 (lower) there is an effect on the current when using a distorted voltage power supply. It is obvious the effect of the FT and PO waveform distortions. They affect mainly the dynamics of the power controller, resulting in a current distortion in the harmonic range, as can be observed in Fig. 10, taken the CHB-PS configuration as reference. This distortion is caused by the chosen current controller, which presents a poor performance in the presence of periodic disturbances.

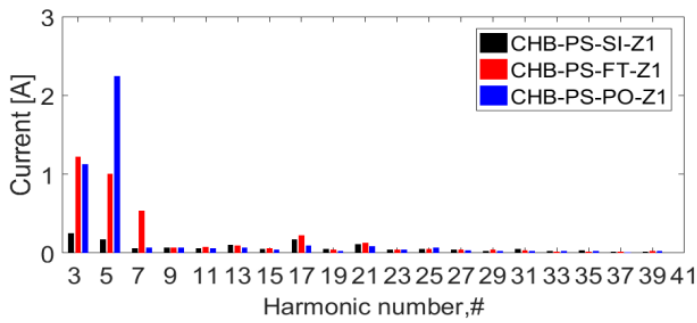

Fig. 10. Harmonics in the presence of voltage waveform distortion on the power supply for CHB-PS configurations.

Table $\mathrm{V}$ presents the calculated results for the Total Supraharmonics Distortion $\left(T S H D_{I}\right)$ in the range 2 - 150 kHz. To compute it, individual $200 \mathrm{~Hz}$ spectrum components, in the range 0 to $150 \mathrm{kHz}$ were grouped according to Annex B of [20] and referenced to the rated current.

Table V - Total Supraharmonic Distortion of current $\left(T S H D_{I}\right)$, expressed as a percentage of the rated current.

\begin{tabular}{|c|c|c|c|c|c|c|}
\hline \multirow{2}{*}{$\begin{array}{l}\text { Source } \\
\text { Supply }\end{array}$} & \multirow{2}{*}{$\begin{array}{l}\text { Network } \\
\text { Config. }\end{array}$} & \multicolumn{3}{|c|}{ NPC } & \multirow{2}{*}{$\begin{array}{l}\text { FC } \\
\text { FS }\end{array}$} & \multirow{2}{*}{$\frac{\mathrm{CHB}}{\mathrm{FS}}$} \\
\hline & & PD & POD & APOD & & \\
\hline SI & $\mathrm{Z1}$ & 0.207 & 0.207 & 0.206 & 0.033 & 0.087 \\
\hline FT & $\mathrm{Z1}$ & 0.197 & 0.198 & 0.197 & 0.045 & 0.064 \\
\hline PT & $\mathrm{Z1}$ & 1 & 0.211 & 13 & 0.036 & 0.080 \\
\hline SI & $\mathrm{Z} 2$ & 207 & 0.207 & 0.206 & 0.026 & 0.089 \\
\hline FT & $\overline{\mathrm{Z} 2}$ & 0.198 & 0.196 & 0.197 & 0.031 & 0.059 \\
\hline PT & $\mathrm{Z} 2$ & 0.211 & 0.212 & 0.213 & 0.043 & 0.096 \\
\hline
\end{tabular}

The results fulfil the requirements from IEEE-1547 [16], being all results below $0.3 \%$.

Fig. 11 illustrates the magnitude spectrum comparing the results for the best and the worst setup configurations (FC-PS-SI-Z1 and NPC-APOD-PO-Z2 respectively), taken $T S H D_{I}$ as reference.

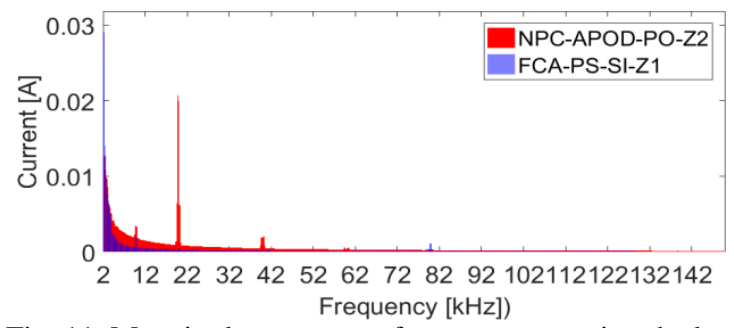

Fig. 11. Magnitude spectrum of current comparing the best and the worst setup configurations.

There is a good match between the simulation and a real measurement taken from a commercial $2.5 \mathrm{~kW}$ PV inverter, illustrate on Fig. 12.

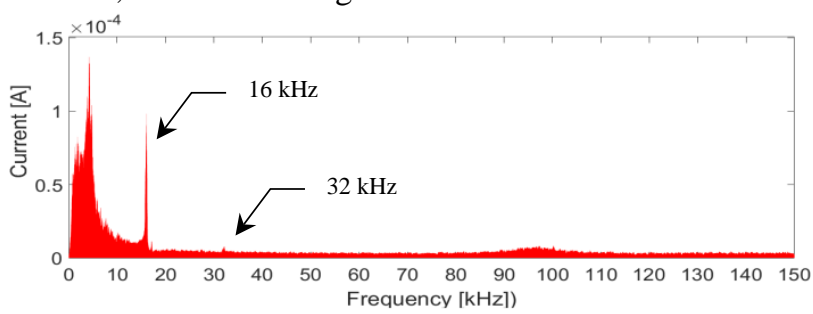

Fig. 12. Magnitude spectrum of current taken from a $2.5 \mathrm{~kW}$ commercial PV inverter.

It is clearly evident the presence of the main switching frequency at $16 \mathrm{kHz}$ and its multiples (e.g. $32 \mathrm{kHz}$ highlighted in Fig. 12), what suggest something similar to the configuration NPC-APOD-PO-Z2.

From the simulation results above, it is clear that the influence of external factors has a huge influence on the 
operation performance of the converters. From a small TSHD $_{I}$ value of (e.g. $3.07 \%$ for CHB-PS-SI-Z2) is possible to reach a high-level in the presence of voltage waveform distortion (e.g. 23.03\% for FC-PS-PO-Z2). Also, as can be observed, the set of combinations between inverter topologies and modulation strategies play a relevant role in the emissions in the supraharmonics range.

\section{Conclusion}

In this paper, an analysis of harmonic supraharmonic emission on multi-level converter was carried out. The paper presented a study to further understand the interaction between the inverters and the grid. The most commonly used topologies and control strategies were selected for simulation.

From the outcome of the investigation it is possible to highlight three main aspects. First, the choice of the multi-level inverter topology has an expressive influence on the emission in the supraharmonics range. Second, the influence of the voltage waveform distortion, on the connection point, affects mainly the harmonic range, especially the $3^{\text {rd }}, 5^{\text {th }}$ and $7^{\text {th }}$ harmonic orders. As a result, a current controller presenting better performance becomes necessary to mitigate this drawback. Finally, for NPC topologies, there is no expressive difference on emissions related to the choice of the modulation strategies used in this work.

The findings are of direct practical relevance. The results from the simulation can be used as reference for the improvement of future power converter designs, serving also as reference for definition of compliances limits, and better characterization of harmonics and supraharmonics impacts.

\section{References}

[1] Photovoltaic Power Systems Programme, Annual Report 2015, IEA International Energy Agency, IEA-PVPS, 2015.

[2] S. Rönnberg, "Emission and interaction from domestic installations in the low voltage electricity network, up to 150 kHz," Ph.D. dissertation, Luleå University of Technology, 2013.

[3] F. Abid, T. Busatto, S. Rönnberg, M. H. J. Bollen "Intermodulation due to interaction of photovoltaic inverter and electric vehicle at supraharmonic range", in Proc. Int. Conference on Harmonics and Quality of Power, ICHQP, Belo Horizonte, Brazil, 2016.

[4] T. Busatto, A. Larsson, M. H. J. Bollen, G. Singh "Interaction between Grid-Connected PV systems and LED Lamps: Directions for Further Research on Harmonics and Supraharmonics” in Proc. Int. Conference on Harmonics and Quality of Power, ICHQP, Belo Horizonte, Brazil, 2016.

[5] S. Rönnberg, A. Larsson, M. Bollen, and J.-L. Schanen, “A simple model for interaction between equipment at a frequency of some tens of $\mathrm{kHz}$," in Proc. Int. Conf. Electricity Distribution (CIRED), Frankfurt, Germany June 2011.

[6] Electromagnetic compatibility (EMC) - Part 3-2: Limits Limits for harmonic current emissions (equipment input current $\leq 16$ A per phase), IEC Standard 61000-3-2, May. 2014.

[7] M. Bollen, J. Meyer, H. Amaris, A. M. Blanco, J. D. Aurora Gil de Castro, M. Klatt, Łukasz Kocewiak, S. Rönnberg, and $\mathrm{K}$. Yang, "Future work on harmonics - some expert opinions
Part I - wind and solar power,” in Harmonics and Quality of Power (ICHQP), 2014 IEEE 16th International Conference on, Bucharest, May 2014.

[8] E. Larsson, M. Bollen, M. Wahlberg, C. Lundmark, and S. Ronnberg, "Measurements of High-Frequency (2-150 $\mathrm{kHz}$ ) Distortion in Low-Voltage Networks," Power Delivery, IEEE Transactions on, vol. 25, no. 3, pp. 17491757, July 2010.

[9] A. McEachern, Electric Power Definitions: a Debate, IEEE Power and Energy Society General Meeting, Vancouver, Canada, 2013.

[10] M. Hankaniemi, T. Suntio, and M. Karppanen, "Load and supply interactions in VMC-buck converter operating in CCM and DCM," in Power Electronics Specialists Conference, 2006. PESC 06. 37th IEEE, June 2006.

[11] A. Yazdani, R. Iravani, Voltage-Sourced Converters in Power Systems: Modeling, Control, and Applications, 1st Edition, John Wiley \& Sons, Inc., 2010

[12] Grahame D. Holmes and Thomas A. Lipo, 2003, "Pulse width modulation for power converters: principles and practice," IEEE Press, Series on Power Engineering

[13] A. M. Blanco, R. Stiegler, J. Meyer, "Power Quality Disturbances caused by Modern Lighting Equipment (CFL and LED)", PowerTech (POWERTECH), 2013 IEEE Grenoble, Grenoble, 2013, pp. 1-6.

[14] Energy Generation Equipment Connected to the Low Voltage Grid, Guideline for the Connection and Parallel Operation of Energy Generation Equipment on Low Voltage Grid), Verband der Elektrizittswirtschaft VDEW e. V., 2001.

[15] Remus Teodorescu; Marco Liserre; Pedro Rodríguez, "Grid Filter Design," in Grid Converters for Photovoltaic and Wind Power Systems , 1, Wiley-IEEE Press, 2011, pp.289-312.

[16] IEEE Std 1547-2003, Standard for Interconnecting Distributed Resources with Electric Power Systems, in IEEE Std 1547-2003, vol., no., pp.1-28, July 282003.

[17] Electromagnetic compatibility (EMC) - Part 4-13: Testing and measurement techniques - Harmonics and interharmonics including mains signalling at a.c. power port, low frequency immunity tests, IEC Standard 610004-13, Jul. 2009.

[18] J. H. R. Enslin et al., "Harmonic interaction between large numbers of photovoltaic inverters and the distribution network," 2003 IEEE Bologna Power Tech Conference Proceedings,, 2003, pp. 6 pp. Vol.3-.

[19] IEC Tech. Rep. 6072, "Consideration of reference impedances and public supply network impedances for use in determining the disturbance characteristics of electrical equipment having a rated current $\leq 75$ A per phase", 2005.

[20] IEC 61000-4-7 Ed. 2.1 "Electromagnetic compatibility (EMC) - part 4-7. Testing and measurement techniques General guide on harmonics and interharmonics measurements and instrumentation, for power supply systems and equipment connected thereto”, IEC, 2008.

[21] A. Moreno Munoz, A. Gil de Castro, S. Rönnberg, M. Bollen, "Supraharmonics (2 to $150 \mathrm{kHz}$ ) and multilevel converters”, 5th Int. Conf. on Power Engineering, Energy and Electrical Drives, POWERENG, 2015. 